\title{
Detection of metabolic syndrome burden in healthy young adults may enable timely introduction of disease prevention
}

\author{
Anja Šoštarič ${ }^{1}$, Barbara Jenko 2 , Nada Rotovnik Kozjek ${ }^{2,3}$, Darja Ovijač ${ }^{1}$, Dušan Šuput ${ }^{4}$, \\ Irina Milisav ${ }^{1,4}$, Vita Dolžan ${ }^{2}$
}

\begin{abstract}
${ }^{1}$ Faculty of Health Sciences, University of Ljubljana, Ljubljana, Slovenia
${ }^{2}$ Institute of Biochemistry, Faculty of Medicine, University of Ljubljana, Ljubljana,

Slovenia

${ }^{3}$ Institute of Oncology, Ljubljana, Slovenia

${ }^{4}$ Institute of Pathophysiology, Faculty of Medicine, University of Ljubljana, Ljubljana, Slovenia
\end{abstract}

Submitted: 22 December 2017

Accepted: 3 March 2018

Arch Med Sci 2019; 15 (5): 1184-1194

DOI: https://doi.org/10.5114/aoms.2019.87462

Copyright (c) 2019 Termedia \& Banach

\section{Abstract}

Introduction: Metabolic syndrome and associated diseases are a global health problem. Detection of early metabolic modifications that may lead to metabolic syndrome would enable timely introduction of preventive lifestyle modifications.

Material and methods: In total 103 young, healthy adults were assessed for indicators of metabolic alterations. Anthropometric, lifestyle, genetic and biochemical parameters were assessed. Individuals who fulfilled at least one criterion for diagnosis of metabolic syndrome were assigned to the group with the higher metabolic syndrome burden (B-MeS).

Results: The 34 young healthy individuals who were assigned to the B-MeS group had lower fat-free mass, higher body mass index, waist-to-hip ratio, fat mass, and blood pressure, more visceral fat, they were less physically active, had higher $\mathrm{C}$-reactive protein values and higher catalase activity. Their phenotype was more similar to that of patients diagnosed with metabolic syndrome than the rest of the population.

Conclusions: Simple anthropometric measurements, lifestyle assessment and basic biochemical measurements can be used to identify young healthy individuals with increased risk for metabolic syndrome. These assessments can be performed at periodic check-ups of the healthy population so that timely diagnosis of B-MeS can be made. As lifestyle factors have a big influence on development or improvement of the MeS, the timely diagnosis for B-MeS would enable an early opportunity for intervention for lifestyle modification in the still healthy population, saving costs and reducing disability adjusted life years.

Key words: metabolic syndrome, young adults, anthropometry, nutrition, exercise.

\section{Introduction}

Some modern types of lifestyle, including sedentary behaviour with overconsumption of caloric food rich in simple sugars, significantly contribute to metabolic and age-related diseases with preceding pathophys-

\author{
Corresponding author: \\ Irina Milisav \\ Institute of \\ Pathophysiology \\ Faculty of Medicine \\ University of Ljubljana \\ Ljubljana, Slovenia \\ Phone: +386-1-543-7089 \\ E-mail: irina.milisav@mf. \\ uni-lj.si
}


iological changes such as hyperglycaemia, obesity, hypertension, dyslipidaemia and a pro-inflammatory state associated with accumulation of adipose tissue [1]. The combination of these changes is called metabolic syndrome (MeS); clinical criteria for diagnosing it include criteria for insulin resistance, central obesity, elevated blood pressure and dyslipidaemia (Table I). MeS is diagnosed when three or more criteria are fulfilled. The criteria for MeS diagnosis of different international organizations are described in Table I.

MeS is associated with increased risk of developing diabetes mellitus type 2 , atherosclerosis and myocardial infarction [2, 3]. According to the samples from the general population using definitions of the metabolic syndrome developed by the National Cholesterol Education Program (NCEP) and World Health Organization (WHO), MeS presents a $30-52 \%$ risk for the development of diabetes mellitus, $12-17 \%$ for cardiovascular disease and 6-7\% risk for all-cause mortality $[4,5]$. The prevalence of MeS of $24 \%$ in the U.S. adults, aged 20 to 70 years, reported in 2002 [6], was surpassed in many countries around the world by 2007, e.g. South Africa of 33.5\%, Turkey $33.4 \%$, Iran 33.7\%, Venezuela $31.2 \%$ and urban Brazil 25.4\% [7-9]. A high proportion of the population with MeS was also reported elsewhere: in parts of China (Shanghai 23\%), urban south India $26 \%$, and a part of Mexico 27\% [7]. No industrialized part of the world is spared; the prevalence of
MeS was 14\% in Finnish adults of 24 to 39 years in 2007 [10]. The MeS prevalence increases with age, as for example $24 \%$ of U.S. adults had MeS in the group of $20-70$ years and $40 \%$ of subjects over 60 years according to the data from 2004 [6]. Another study published in 2009 based on the data of the National Health and Nutrition Examination Survey (NHANES) 2003-2006 reported the overall prevalence of MeS in the US in adults over 20 years as $34 \%$, with large differences between age groups: individuals of 40-59 years of age were about three times as likely as those of 20-39 years of age to meet the criteria for metabolic syndrome diagnosis [11]. Large gender-specific differences were seen in the oldest group; males of 60 years of age and over were more than four times and females six times as likely to be diagnosed with MeS, respectively.

Visceral (splanchnic) obesity has been established as an important factor in development of MeS [12, 13]. While genetic and environmental influences contribute to MeS development, the major risk factors are chronic caloric overnutrition, possibly with high fructose intake [12, 14], and physical inactivity $[15,16]$.

At the molecular level, elevated mitochondrial oxidative stress is frequently associated with MeS and may contribute to its development [1]. The superoxide radical, generated by mitochondria, is dismutated rapidly to hydrogen peroxide by manganese superoxide dismutase (MnSOD), which is present at high concentrations in the mitochon-

Table I. MeS criteria. For MeS diagnosis 3 of the following criteria must be fulfilled (WHO criteria: insulin resistance criterion and 2 others). The individuals with the values above the most stringent threshold of measured criteria (bolded) were assumed to have the higher MeS burden (B-MeS) in this study

\begin{tabular}{|c|c|c|c|c|c|c|}
\hline Criteria & Anthropometric & Triglycerides & HDL-C & BP & FG & UAE \\
\hline $\begin{array}{l}\text { WHO, } \\
1998\end{array}$ & $\begin{array}{c}\mathrm{BMI}>30 \mathrm{~kg} / \mathrm{m}^{2} \\
\mathrm{~W} / \mathrm{H}>0.9 \text { male } \\
\mathrm{W} / \mathrm{H}>0.85 \\
\text { female }\end{array}$ & $\begin{array}{l}\geq 150 \mathrm{mg} / \mathrm{dl} \\
(1.7 \mathrm{mmol} / \mathrm{l})\end{array}$ & $\begin{array}{c}<35 \mathrm{mg} / \mathrm{dl} \mathrm{male} \\
(0.9 \mathrm{mmol} / \mathrm{l}) \\
<39 \mathrm{mg} / \mathrm{dl} \\
\text { female } \\
(1 \mathrm{mmol} / \mathrm{l})\end{array}$ & $\begin{array}{c}\geq 140 / 90 \mathrm{~mm} \mathrm{Hg} \\
\text { medication }\end{array}$ & $\begin{array}{c}<110 \mathrm{mg} / \mathrm{dl} \\
(6.1 \mathrm{mmol} / \mathrm{l}), \\
\text { T2DM, } \\
\text { impaired glucose } \\
\text { tolerance }\end{array}$ & $\geq 20 \mu \mathrm{g} / \mathrm{min}$ \\
\hline $\begin{array}{l}\text { ATP-III, } \\
2001\end{array}$ & $\begin{array}{l}W C>102 \text { male } \\
W C>88 \text { female }\end{array}$ & $\begin{array}{l}\geq 150 \mathrm{mg} / \mathrm{dl} \\
(1.7 \mathrm{mmol} / \mathrm{l})\end{array}$ & $\begin{array}{c}<40 \mathrm{mg} / \mathrm{dl} \\
(1 \mathrm{mmol} / \mathrm{l}) \mathrm{male} \\
<50 \mathrm{mg} / \mathrm{dl} \\
(1.3 \mathrm{mmol} / \mathrm{l}) \\
\text { female }\end{array}$ & $>130 / 85 \mathrm{~mm} \mathrm{Hg}$ & $\begin{array}{l}\geq 110 \mathrm{mg} / \mathrm{dl} \\
(6.1 \mathrm{mmol} / \mathrm{l})\end{array}$ & l \\
\hline IDF & $\begin{array}{c}W C \geq 94 \mathrm{~cm} \\
\text { male } \\
W C \geq 80 \mathrm{~cm} \\
\text { female }\end{array}$ & $\begin{array}{c}\geq 150 \mathrm{mg} / \mathrm{dl} \\
(1.7 \mathrm{mmol} / \mathrm{l}) \\
\text { medication }\end{array}$ & $\begin{array}{c}<40 \mathrm{mg} / \mathrm{dl} \\
(1 \mathrm{mmol} / \mathrm{l}) \mathrm{male} \\
<50 \mathrm{mg} / \mathrm{dl} \\
(1.3 \mathrm{mmol} / \mathrm{l}) \\
\text { female }\end{array}$ & $\begin{array}{c}\text { 130/85 mm Hg, } \\
\text { medication }\end{array}$ & $\begin{array}{c}\geq 100 \mathrm{mg} / \mathrm{dl} \\
(5.6 \mathrm{mmol} / \mathrm{l}), \\
\text { T2DM }\end{array}$ & / \\
\hline $\begin{array}{l}\text { Consensus, } \\
2009\end{array}$ & $\begin{array}{c}\text { WC cut-off } \\
\text { population and } \\
\text { country specific }\end{array}$ & $\begin{array}{c}\geq 150 \mathrm{mg} / \mathrm{dl} \\
(1.7 \mathrm{mmol} / \mathrm{l}) \\
\text { medication }\end{array}$ & $\begin{array}{c}<40 \mathrm{mg} / \mathrm{dl} \\
(1 \mathrm{mmol} / \mathrm{l}) \mathrm{male} \\
<50 \mathrm{mg} / \mathrm{dl} \\
(1.3 \mathrm{mmol} / \mathrm{l}) \\
\text { female }\end{array}$ & $\begin{array}{c}\geq 130 / 85 \mathrm{~mm} \mathrm{Hg} \\
\text { drug treatment }\end{array}$ & $\begin{array}{c}\geq 100 \mathrm{mg} / \mathrm{dl} \\
(5.6 \mathrm{mmol} / \mathrm{l}) \\
\text { drug treatment }\end{array}$ & I \\
\hline
\end{tabular}

BP - blood pressure, FG - fasting glucose, UAE - urinary albumin excretion, WC - waist circumference, W/H - waist-to-hip ratio, ATP-III National Cholesterol Education Program (NCEP) Adult Treatment Panel III, Consensus - consensus between IDF-AHA/National Heart Lung and Blood Institute, IDF - International Diabetes Federation, WHO - World Health Organization. 
drial matrix [17]. The matrix hydrogen peroxide is degraded by glutathione peroxidase 1 (GPX1) and peroxiredoxin III [18], and diluted by its diffusion out of the mitochondrion. Catalase (CAT) is another enzyme that protects cells from reactive oxygen species (ROS) by removal of hydrogen peroxide. Single nucleotide polymorphisms (SNPS) in genes encoding the antioxidant enzymes may change the amounts or activity of these enzymes. The CAT rs1001179 polymorphism in the transcription factor binding site (c.-262 C>T) promotes transcription of the $T$ allele to result in increased translation [19]; however, the relationship between the polymorphism and the enzyme activity is complex [20]. MnSOD rs4880 (p.Ala16Val) reduces activity of mitochondrial SOD [21]; GPX1 rs 1050450 polymorphism (p.Pro198Leu) also results in a less active variant [22].

ROS also regulate expression of proteins involved in inflammation, immune response and cell death [23]. Chronic inflammation is common in obesity and contributes to insulin resistance and diabetes mellitus type 2 [24]. Pathogen- or damage-associated signals, such as ROS, also contribute to assembly and activation of NLRP3 inflammasomes [25]. When activated, these protein complexes activate caspase- 1 that processes pro-interleukin-1 $\beta$ to interleukin-1 $\beta$ (IL-1 $\beta$ ) thus initiating downstream inflammatory responses [24]. NLRP3 inflammasome activation is associated with insulin resistance, circulating immune markers, macrophage function and chronic inflammation. SNPs of inflammasome components, NLRP3 rs35829419 (p. Gln705Lys) and CARD8 rs2043211 (p. Cys10Ter), were both associated with proinflammatory phenotype [24, 26, 27]. NLRP3 Gln705Lys phenotype results in increased production of IL-1 $\beta$ [28], while the polymorphism causing a non-functional CARD8 protein leads to loss of inhibition of caspase-1; the truncated protein does not prevent NF- $\mathrm{KB}$ stimulation of the inflammatory response [29]. This CARD8 polymorphism had no effects on cytokine profiles in a cohort of healthy blood donors [26]. CARD8 rs2043211 T allele reduced the risk of ischemic stroke, but not of coronary artery disease [30].

As detection of signs and symptoms that belong to the clinical criteria for MeS is important because of the likelihood of developing the associated diseases, it is of great importance to identify early markers of increased risk of developing the MeS in healthy population of young adults of about 20 years. Such markers could be assessed during the periodic health check-ups to detect individuals at risk of developing MeS (with the MeS burden, B-MeS) [31] in order to start lifestyle modifications as early as possible. This would enable timely counselling/lifestyle modification ad- vice to still healthy individuals for prevention or delay of clinical symptoms referred to as MeS and of MeS-associated diseases. We performed a pilot study to assess the indicators of early metabolic alterations in young healthy adults to identify individuals with a higher metabolic syndrome burden who may benefit from timely introduction of preventive lifestyle modifications.

\section{Material and methods}

First year students of the Nursing programme at the University of Ljubljana, Faculty of Health Sciences were invited to participate in the study. The participants had no formal or informal training on MeS development and the importance of lifestyle choices prior to participation in the study. All subjects were informed of the study aims and were included after signing a written informed consent form. The study was approved by the Slovenian Ethics Committee for Research in Medicine and was conducted in compliance with the Helsinki Declaration.

All participants agreed to be surveyed and to donate a peripheral blood sample for biochemical and genetic analyses. Anthropometric measurements and dietary and exercise habits were recorded on the day of recruitment. Height, weight, waist and hip circumferences, blood pressure and two-compartment body composition were measured and body mass index (BMI) was calculated. A single frequency bioelectrical impedance analysis (BIA) at $50 \mathrm{kHz}$ by Omron HBF-511 was used to determine the two-compartment body composition; BIA was performed always in the afternoon at least $2 \mathrm{~h}$ after a meal. Amounts of visceral fat were calculated from BIA measurements by an inbuilt Omron algorithm (arbitrary scale 1-30).

The individuals who met at least one criterion for diagnosis of MeS were assumed to have higher MeS burden (B-MeS). For assignment, the most stringent criteria for metabolic syndrome diagnosis were used: the waist circumference larger than 85 and $94 \mathrm{~cm}$ for women and men, respectively, waist-to-hip ratio larger than 0.85 and 0.9 for women and men, respectively, BMI more than $30 \mathrm{~kg} / \mathrm{m}^{2}$ and blood pressure above or equal to 130/85 mm Hg (Table I).

Lifestyle and socioeconomic status was inferred from the questionnaire that included questions on diet, exercise, education level and social status. The highest education level reached by any parent in the family was set as the parent's education. Diet was assessed by a food frequency questionnaire (FFQ) section composed of 36 individual food items, in total 9 categories of beverages and alcoholic drinks and questions on consumption of pre-processed food, fast food and food supplements. The FFQ section was derived from the 
questionnaires used for Spanish (Alimentacion y Salud 2.0) [32, 33] and Brazilian populations [34] that were adapted to local foods and eating habits.

Leukocytes were isolated from blood, genomic DNA was extracted by the FlexiGene DNA Kit (QIAGEN, Hilden, Germany) and genotyped for inflammasome (NLRP3 rs35829419, CARD8 rs2043211) and antioxidant genes (CAT rs1001179, MnSOD rs4880 and GPX1 rs1050450) polymorphisms using fluorescence-based competitive allele-specific polymerase chain reaction (KASP assays, LGC group, Teddington, UK). Catalase activity was determined from plasma of 84 individuals by a Catalase assay kit (Cayman Chemical). C-reactive protein (CRP) was measured by CRP (Latex) HS assay (Roche Diagnostics).

\section{Statistical analysis}

The median was used to present the central tendency with the $25^{\text {th }}$ to $75^{\text {th }}$ percentile range as a measure of variability. The $\chi^{2}$ test was used to assess Hardy-Weinberg equilibrium (HWE) and to compare proportions between groups. The Mann-Whitney test was used to assess significance between the groups of non-parametric variables (age). Logistic regression was used to assess statistical significance ( $p$-value), odds ratio (OR) and $95 \%$ confidence interval $(95 \% \mathrm{Cl})$ between individuals who were assigned to a higher risk group for MeS development and controls. All significance tests were two-tailed and conducted at the 0.05 level of significance. Analyses were performed using R (R Core Team (2014)).

\section{Results}

Out of 103 young, healthy Caucasian individuals included in our study, 81\% were women. The median age of the study group was 20 years (25-75\%, range: 20-22 years). Anthropometric parameters and blood pressure are routinely measured at the periodic health evaluations of the Slovenian population; therefore, these parameters were used to estimate the higher MeS burden (B-MeS, Table I). Thirty-four (33\%) individuals, 28 (82\%) women and 6 men, above the cut-off values for one of these parameters, were assigned to the B-MeS group. Gender and age did not differ significantly between the B-MeS and other individuals, i.e. controls ( $p=0.75, p=0.07$, respectively).

The percentage of fat free mass (FFM) of all participants measured by single frequency bioelectrical impedance analysis (BIA) was relatively homogeneous, with a median (25-75\% range) of $29.3 \%$ (27.5-32.6\%). Nevertheless, the participants in the B-MeS group had lower FFM, with a median of $27.7 \%(25.9-31.0 \%)$ compared to the control group with $30.0 \%(28.2-33.7 \%)(p=0.012$; OR = 0.88; 95\% Cl: 0.79-0.96) (Figure 1). The percent- age of fat mass (FM) was more varied among all participants, with a median of 30\% (22.9-35.3\%). The B-MeS group had a significantly higher percentage of FM $(p=0.0006 ; \mathrm{OR}=1.11 ; 95 \% \mathrm{Cl}$ : 1.05-1.18), as the B-MeS group had median FM of $34.5 \%$ (26.9-38.7\%), while the control group had $26.9 \%(22.5-32.8 \%)$. The median visceral fat was 4 arbitrary units (3-5), considered in the normal range by the manufacturer. The B-MeS group also had significantly higher visceral fat values, with a median of 4 (3.2-6.7) vs. 3 (2-4) in the group without an MeS burden ( $p=0.0004$; OR = 1.58; 95\% Cl: 1.25-2.09). Although 27 (26.2\%) participants had a BMI equal to 25 or above, only 8 (7.7\%) of them considered themselves overweight (Figure 1). Higher BMI values can be calculated also in individuals with high FFM; therefore the participants were divided further into two groups, according to the amount of the FFM, i.e. below or above the population's median value of $29.2 \%$. Out of 8 participants, 7 men and 1 woman, half of the men (4) and the woman were in the B-MeS group, but no man had the percentage of the FFM above the median calculated for the male population only. About one third of the participants (9) with the BMI equal to or above 25 had FFM above the median value. None of these participants had BMI greater than 30, an inclusion criterion for the B-MeS group.

The median BMI of the B-MeS group was $25 \mathrm{~kg} /$ $\mathrm{m}^{2}\left(22-28.4 \mathrm{~kg} / \mathrm{m}^{2}\right)$ compared to $22 \mathrm{~kg} / \mathrm{m}^{2}(19.8-$ $\left.23.4 \mathrm{~kg} / \mathrm{m}^{2}\right)$ in the rest of the participants $(p<$ $0.0001 ; \mathrm{OR}=1.36,95 \% \mathrm{Cl}: 1.18-1.61$ ) (Figure 2). Nevertheless, 16 (47\%) individuals in the B-MeS group were not overweight; i.e. their BMI was lower than $25 \mathrm{~kg} / \mathrm{m}^{2}$. Seven out of 34 (20\%) B-MeS participants, 5 women and 2 men, exceeded the MeS threshold for waist-to-hip ratio. The waist-tohip ratio of the rest of the B-MeS participants who did not exceed the MeS threshold was also higher than that of the rest of the participants. There was a significant difference between the groups ( $p=$ $0.0003 ; \mathrm{OR}=8.17 \times 10^{5} ; 95 \% \mathrm{Cl}: 8.37 \times 10^{2}-2.52$ $\left.\times 10^{9}\right)$, with a median of $0.78(0.73-0.84)$ and 0.73 $(0.70-0.77)$ in the participants with B-MeS and the others, respectively (Figure 2).

Half of the participants (17 out of 34) were assigned to the B-MeS group because of the blood pressure above or equal to $130 / 85$ (15 systolic only, 2 diastolic only). The blood pressure in the $\mathrm{B}-\mathrm{MeS}$ group was significantly higher (systolic blood pressure: $p=0.00004$; $\mathrm{OR}=1.14 ; 95 \% \mathrm{Cl}$ : 1.08-1.22; diastolic blood pressure: $p=0.01$; OR $=$ 1.07; 95\% Cl: 1.02-1.13).

Lifestyle factors had a considerable effect on the probability of B-MeS. The family background significantly influenced B-MeS risk, as the education level of participants' parents correlated significantly with the risk for B-MeS status ( $p=0.03$; $\mathrm{OR}=0.49 ; 95 \% \mathrm{Cl}: 0.24-0.89)$. Significantly more 
A

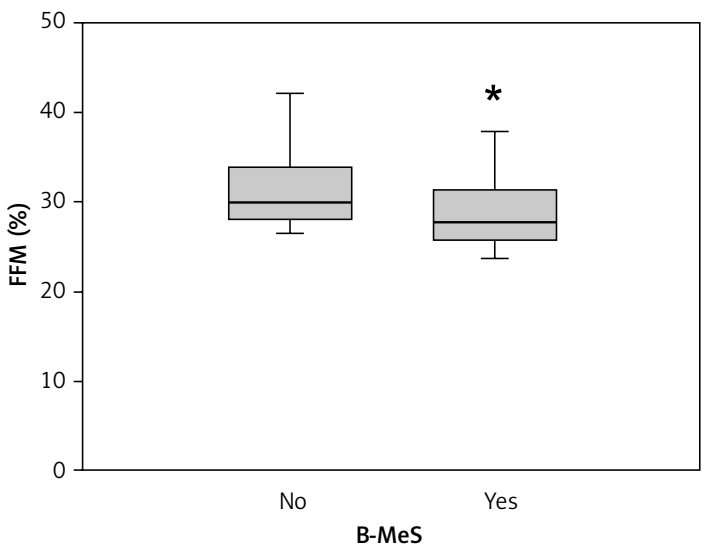

C

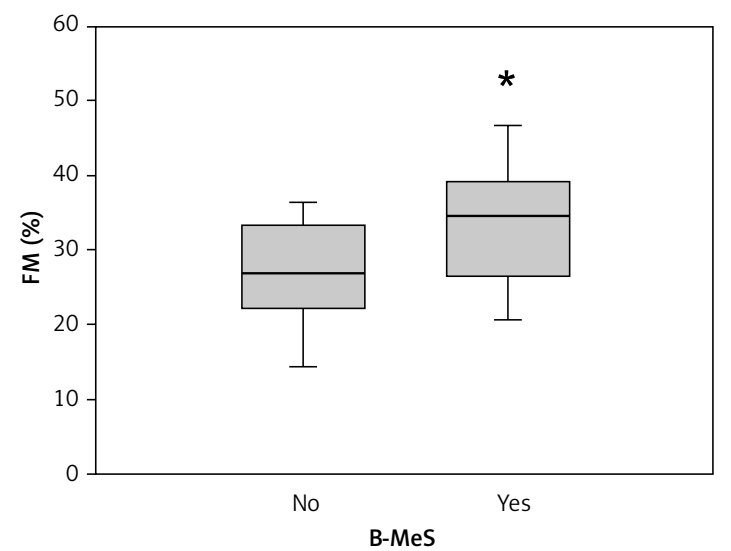

B

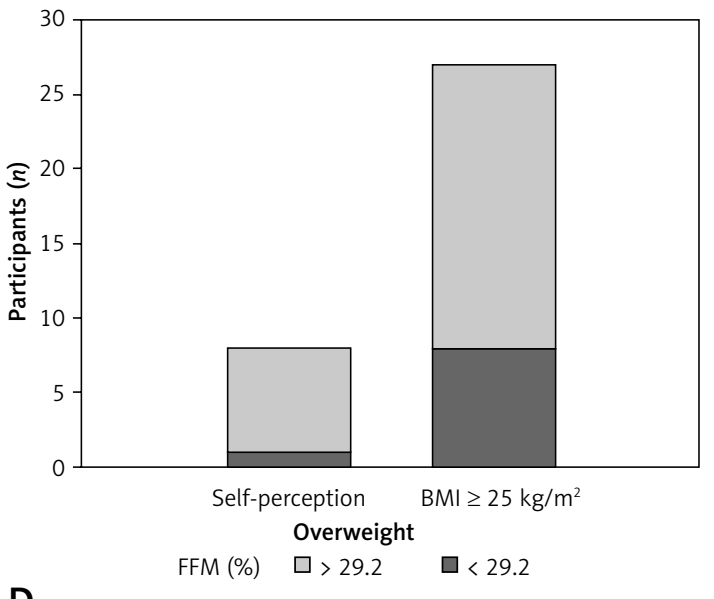

D

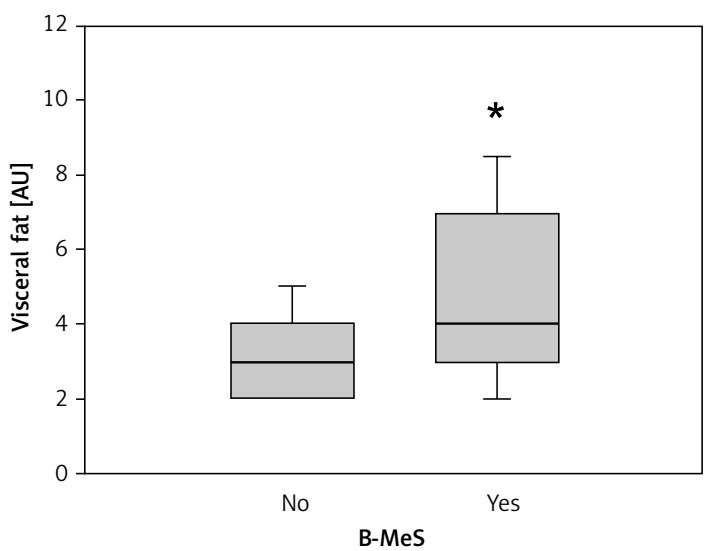

Figure 1. Two-compartment body measurements in participants with and without metabolic syndrome burden (B-MeS). A, C - body composition measured by single frequency BIA. D - amounts of visceral fat. B - number of participants with self-perception of being overweight versus the number of participants with the BMI equal to or above $25 \mathrm{~kg} / \mathrm{m}^{2}$. The amounts of FFM above and below the population's median (29.2\%) are indicated in light and dark grey, respectively

The thin line indicates the median value in box and whisker plots; *statistical significance. FFM - fat free mass, FM - fat mass, $A U$ - arbitrary units, B-MeS - metabolic syndrome burden.

B-MeS individuals had parents with only primary or secondary school education (B-MeS group: $85.3 \%$; other participants: $58 \%)$, while no individual assigned to the B-MeS group had a parent with a BSc or a higher degree (Figure 3).

Exercise and diet also correlated with the probability of B-MeS (Figure 3). The individuals who were more active were less likely to be in the B-MeS group ( $p=0.012$; OR $=0.54 ; 95 \% \mathrm{Cl}$ : $0.33-0.86)$. Most of the individuals consumed fast food meals occasionally. The median number of fast food meals per month was 3 (range: 1-8) for the participants of the B-MeS group and 1 (range: 0.25-4) for the other participants. Therefore, the individuals in the B-MeS group seemed to consume more fast food meals per month, but this difference was not statistically significant. No other close association of increased B-MeS was found with a particular food item or beverage or their combinations.
The distribution of CARD8, NALP3, CAT, GPX1 and SOD2 genotypes did not differ significantly between the B-MeS group and other participants (Table II). On the other hand, biochemical measurements correlated with B-MeS, although all participants had values still within the normal range. The individuals in the B-MeS group had statistically significantly higher enzyme activity of serum catalase $(p=0.024 ; \mathrm{OR}=1.02 ; 95 \% \mathrm{Cl}$ : 1.00-1.05) (Figure 4). Similarly, the CRP values of the individuals in the B-MeS group were significantly higher than in the rest of the participants ( $p=0.05 ; \mathrm{OR}=1.26 ; 95 \% \mathrm{Cl}: 1.01-1.63)$.

\section{Discussion}

We have studied the indicators of early metabolic alterations in young healthy adults to identify the individuals with higher metabolic syndrome burden who may benefit from timely introduction 
A

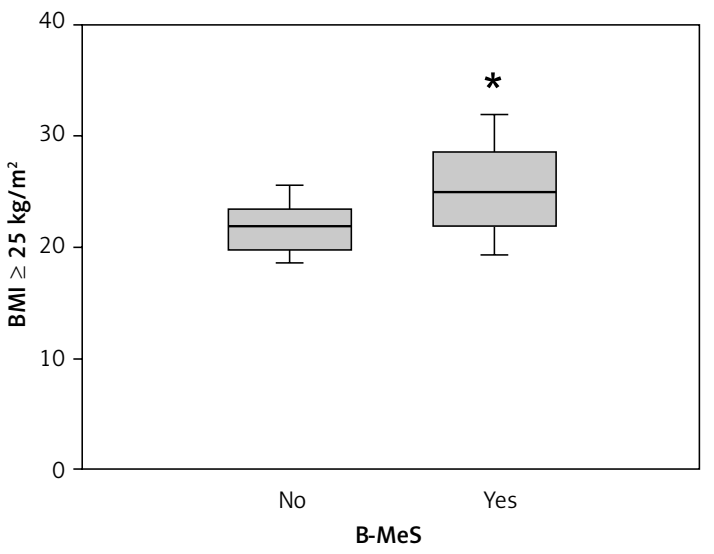

C

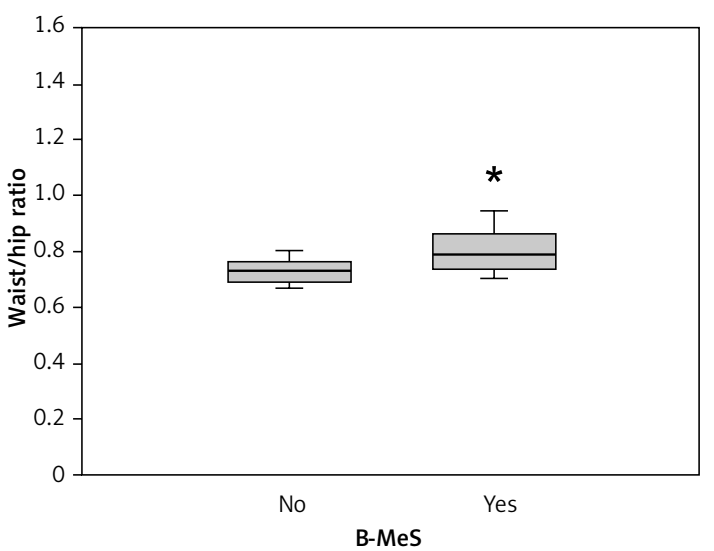

B

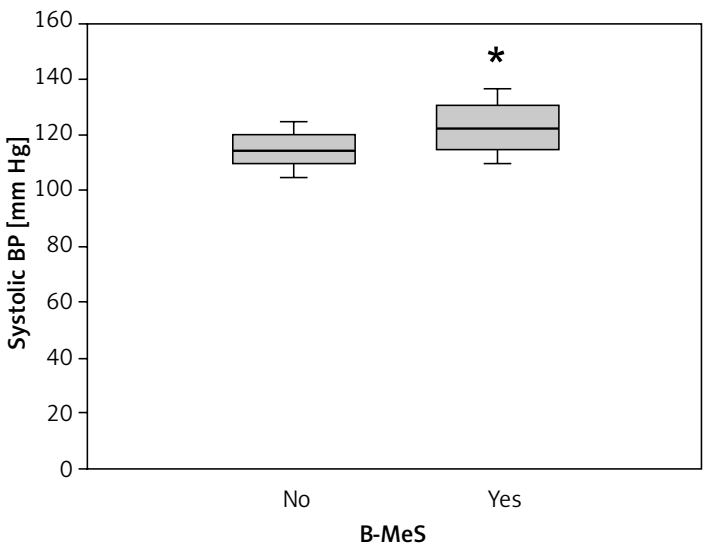

D

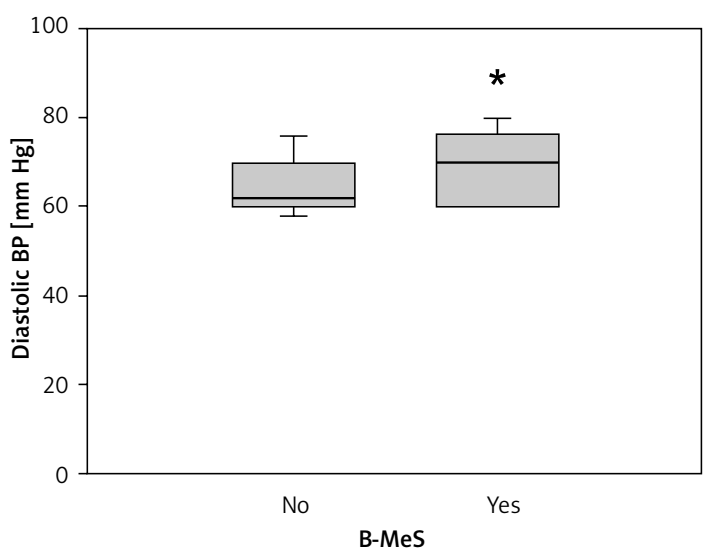

Figure 2. Anthropometric measurements in participants with and without the metabolic syndrome burden The thin line indicates the median value; *statistical significance; $B M I$-body mass index, $B P$ - blood pressure.

of preventive lifestyle modifications. As the participants had no formal or informal training on development of MeS prior to the study, we consider the sample representative of the young adult student population. According to the Statistical Office of the Republic of Slovenia $47 \%$ of the young people between 19 and 24 years are students [35]. The sample thus may be representative for about half of the Slovenian young adult population.

There were about 4 times more female than male participants in our study. We detected no parameter that differed according to gender; therefore, we have presented the data together. Although there are some data that may lead to the conclusion that there are gender differences in MeS prevalence, Zimmet and co-authors discussed in detail the problems of comparing the prevalence data for MeS between the countries and even between studies in the same region, when using MeS syndrome criteria of different international bodies. From 14 studies using the ATPIII definition they concluded that neither sex appeared to have a clearly higher prevalence of the metabolic syndrome [36].
Assessment of anthropometric parameters, lifestyle indicators and laboratory tests has confirmed that the characteristics of the group assigned as B-MeS on the basis of fulfilment of a single diagnostic criterion for MeS were significantly different when compared to the rest of the study participants. The B-MeS group has significantly more FM, including visceral fat, higher waist-tohip ratio, BMI and blood pressure and lower FFM. Similar findings were obtained in other studies. Upper-normal waist circumference was reported as a risk factor for metabolic syndrome in a study of over 173000 normal-weight subjects [37]. Lapice et al. [38] found that among non-obese young people those with abdominal adiposity had an adverse cardiovascular risk factor profile. An association between abdominal obesity and higher risk of MeS was also reported in adolescents [31]. A correlation between waist-to-hip ratio and blood pressure was also reported in a sample of 140 children aged 6-16 [39].

In our study, each individual was placed in the B-MeS group on the basis of fulfilment of the single criterion (the most stringent) for MeS. Nevertheless, the participants in the B-MeS group had 
A

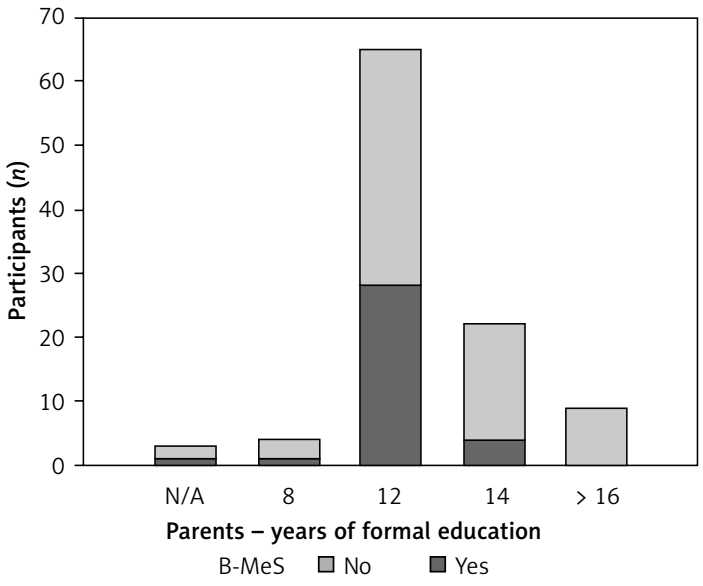

C

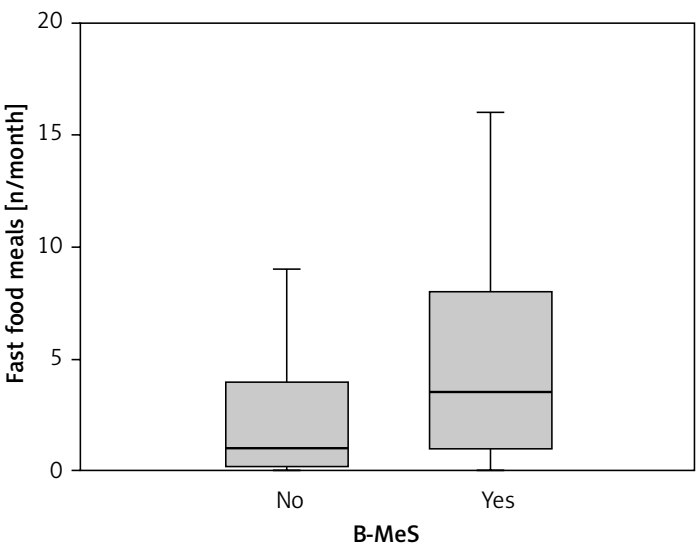

significantly higher median values for all other parameters tested, although still within the normal clinical range. Simple anthropometric measurements were found to suffice for early differentiation of metabolic differences. This agrees with the report that anthropometric measurements were good enough predictors of glycaemia and insulin resistance in the sense that other complex mea-
B

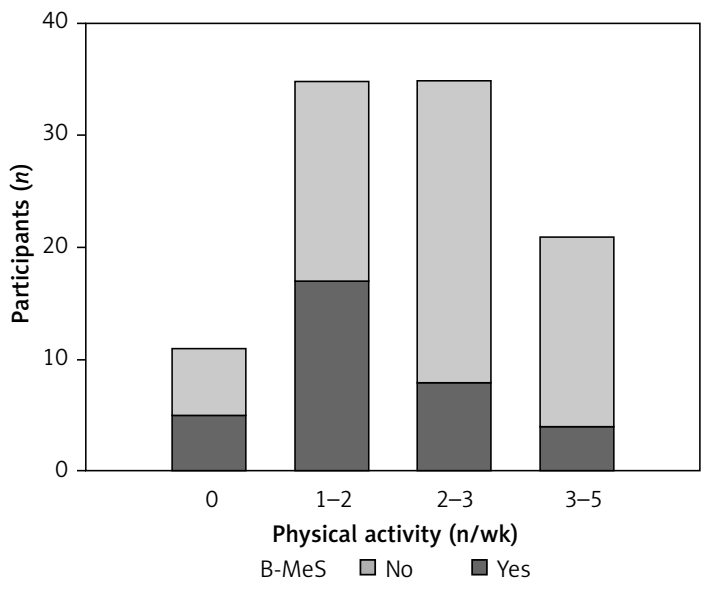

Figure 3. Lifestyle indicators in participants with and without the metabolic syndrome burden

The thin line indicates the median value.

surements such as MRI, DXA and CT contributed little to the prediction of MeS in Indian men [40].

Simple body measurements and body proportions are easily assessed; however, we found that only one third of individuals with BMI values that classify them as overweight considered themselves as overweight. The same metabolic alterations may be present in overweight as well

Table II. Polymorphisms of genes encoding the NRLP3 inflammasome (CARD8, NALP3) and of antioxidant enzymes (CAT: catalase, GPX1: glutathione peroxidase 1, SOD2: superoxide dismutase 2)

\begin{tabular}{|c|c|c|c|c|c|}
\hline Polymorphism & Genotype & B-MeS $(n)$ & Non-B-MeS $(n)$ & $P$-value & OR $(95 \% \mathrm{Cl})$ \\
\hline $\begin{array}{l}\text { CARD8 } \\
\text { rs2043211 }\end{array}$ & $\begin{array}{l}\text { AA } \\
\text { TA } \\
\text { TT }\end{array}$ & $\begin{array}{c}14 \\
17 \\
2\end{array}$ & $\begin{array}{c}36 \\
26 \\
5\end{array}$ & 0.45 & $1.29(0.66-2.52)$ \\
\hline $\begin{array}{l}\text { NALP3 } \\
\text { rs35829419 }\end{array}$ & $\begin{array}{l}\mathrm{CC} \\
\mathrm{CA}\end{array}$ & $\begin{array}{c}32 \\
1\end{array}$ & $\begin{array}{c}60 \\
7\end{array}$ & 0.22 & $0.27(0.14-1.60)$ \\
\hline $\begin{array}{l}\text { CAT } \\
\text { rs1001179 }\end{array}$ & $\begin{array}{l}\text { GG } \\
\text { GA } \\
\text { AA }\end{array}$ & $\begin{array}{c}19 \\
13 \\
1\end{array}$ & $\begin{array}{c}37 \\
24 \\
6\end{array}$ & 0.53 & $0.80(0.39-1.57)$ \\
\hline $\begin{array}{l}\text { GPX1 } \\
\text { rs1050450 }\end{array}$ & $\begin{array}{l}\text { CC } \\
\text { CT } \\
\text { TT }\end{array}$ & $\begin{array}{c}13 \\
19 \\
1\end{array}$ & $\begin{array}{c}37 \\
24 \\
6\end{array}$ & 0.45 & $1.29(0.66-2.52)$ \\
\hline $\begin{array}{l}\text { SOD2 } \\
\text { rs4880 }\end{array}$ & $\begin{array}{l}\text { CC } \\
\text { CT } \\
\text { TT }\end{array}$ & $\begin{array}{c}11 \\
17 \\
5\end{array}$ & $\begin{array}{l}15 \\
35 \\
17\end{array}$ & 0.15 & $0.64(0.34-1.17)$ \\
\hline
\end{tabular}


A

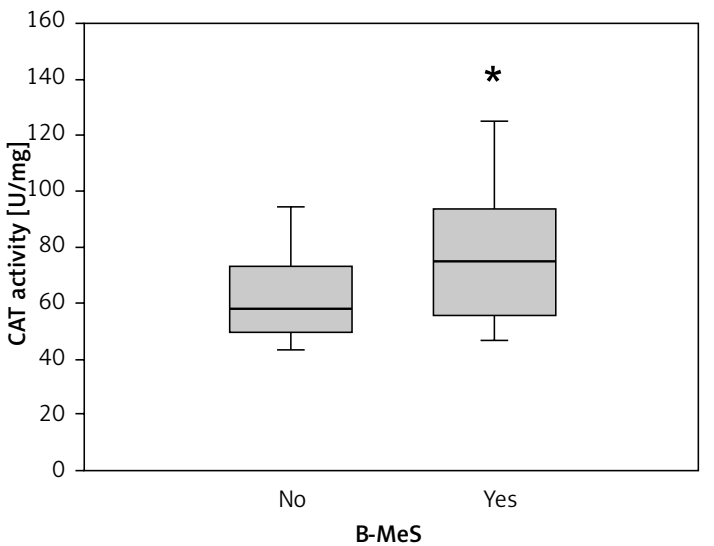

B

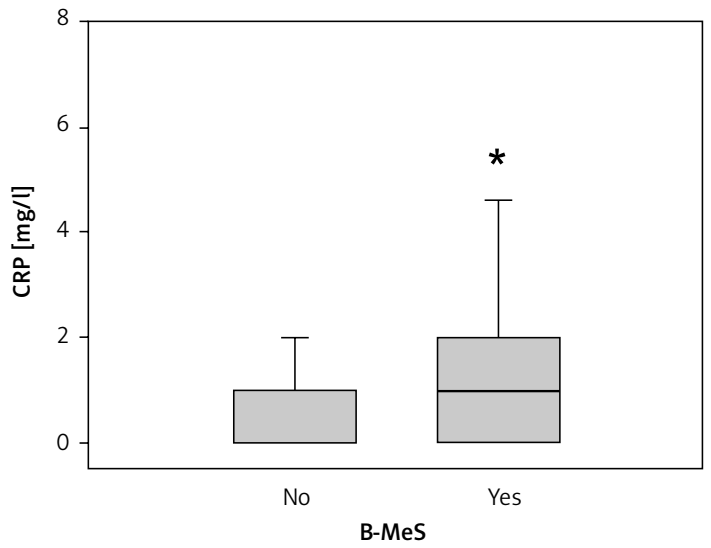

Figure 4. Laboratory parameters in participants with and without the metabolic syndrome burden The thin line indicates the median value; *statistical significance.

as in some lean individuals. It is conceivable that the lean individuals do not notice that they are at risk for MeS, as they perceive their body shape as normal. Therefore, timely assessment by medical professionals is needed.

Lifestyle indicators, such as the amount of physical activity, socio-economic status of the family and diet, also differed between the groups. Our observation that the B-MeS group was less physically active is in agreement with findings of other authors [41-43]. Physical inactivity for only 14 days was reported to reduce the insulin sensitivity in young adult men [16].

Low levels of education of participants' parents correlated with higher B-MeS. This correlation may also be due to the fact that we examined young adults, who have only recently moved away from their parents. Such an influence of socio-economic status was reported before. Socio-economic status was related to morbidity and mortality from diabetes mellitus in ten European countries [44]. It had an effect on the probability of developing MeS also in South Korea, where men with the lowest education level and women with the highest were significantly less likely to have metabolic syndrome [45].

The number of consumed fast food meals that was indicated by the participants tended to correlate with the B-MeS and is in agreement with a report on Iranian children and adolescents where the fast food intake was associated with the incidence of MeS, abdominal obesity, and hypertriglyceridaemia [46]. It is possible that we did not reach statistical significance because of the small number of participants in our study. The dietary fibre intake and carbohydrate quality and quantity were negatively associated with the all-cause and CVD mortality risks in more than 500000 Europeans with confirmed diabetes mellitus [47]. We found no other association of B-MeS and a single or a combination of food ingredients, although such connections were reported from much larger populations, e.g. from more than 15000 participants in the Brazilian study $[48,49]$.

We also assessed the role of genetic factors, but the genotype distribution of polymorphic genes coding for inflammasome or antioxidative enzymes did not differ between the B-MeS individuals and other participants. This may be due to the small study group. Polymorphism in the gene for the pro-inflammatory cytokine IL-6 (SNP rs1800795 G allele) was recently associated with increased odds for MeS in a 3-times larger Brazilian population [50]. Higher inflammation and oxidative stress are generally present in individuals with MeS; therefore, the higher levels in activity of an antioxidative enzyme, plasma catalase, that we observed in the participants of the B-MeS group seem consistent. This seems to agree with the results of Pennathur et al. [51] from 25 non-diabetic subjects with MeS where oxidative stress markers, including serum catalase, decreased after 24week lifestyle intervention. However, higher catalase activity was not always detected. Although oxidative stress was detected in the MeS group, the levels of plasma catalase activity were not increased in the study, which included only $24 \mathrm{MeS}$ and 18 matched controls [52].

Like the participants in our B-MeS group, the metabolic syndrome patients had persistently higher levels of CRP with no clinical symptoms of inflammatory diseases $[53,54]$. Higher CRP was found to correlate with visceral obesity also in non-obese young people $[38,55]$. In a randomized control trial in 52 women with MeS, CRP was lowered only in the group provided with the 6-month therapeutic lifestyle modification (health education and exercise) programme [56]. CRP values were found to oscillate with the menstrual cycle in women [57]. In our study, the CRP levels were 
higher also in the B-MeS group when only male participants were analysed.

Clinical signs of MeS develop over time, as is also seen in its lower prevalence in the younger compared to the older population groups $[6,11$, 58]. Limitations of the current MeS definitions, which are dichotomous, necessitated development of continuous MeS scores that may better represent an aggregated burden for MeS especially in paediatric populations $[31,59,60]$. There is a tendency to simplify the algorithms for calculation of the continuous MeS score; however, this approach will always include calculations to evaluate the MeS burden. We observed here that individuals who fulfilled a single diagnostic MeS criterion had a phenotype significantly more similar to that of the MeS population compared to the rest of the study participants even among the young adults. Therefore, determination of B-MeS as shown here is potentially a practical crude screening method that can be applied at any GP practice. The proportion of the healthy population that fulfilled a single MeS criterion that will progress to the MeS diagnosis needs to be validated and is a limitation of this study.

In conclusion, as lifestyle modification is an efficient measure for the reversal of some MeS parameters [56], early detection of individuals at risk, especially young ones, should improve the health of the population. With the total number of adults with diabetes expected to rise to $6.4 \%$ of the world adult population by 2030 [61] and an estimated 93.6 million disability-adjusted life years related to metabolic problems due to overweight and obesity in 2010 [62], the early attenuation/reversal of metabolic modifications may considerably reduce the healthcare costs. Validation of this pilot study on larger cohorts is needed and assessment of different populations will enable the appropriate population threshold values to be established.

\section{Acknowledgments}

Anja Šoštarič and Barbara Jenko contributed equally to this manuscript.

The authors acknowledge the financial support from the Slovenian Research Agency (research core funding No. P1-0170 and P3-0019). This study was also partially supported by the $\mathrm{H} 2020$ MSCA-ITN:721236 TREATMENT project.

We thank Izak Patrik Miller for assistance with catalase activity measurement and Dr. Blaž Banič for assistance with figure preparation.

\section{Conflict of interest}

The authors declare no conflict of interest.

\section{References}

1. James AM, Collins Y, Logan A, Murphy MP. Mitochondrial oxidative stress and the metabolic syndrome. Trends Endocrinol Metabol 2012; 23: 429-34.

2. Lakka HM, Laaksonen DE, Lakka TA, et al. The metabolic syndrome and total and cardiovascular disease mortality in middle-aged men. JAMA 2002; 288: 2709-16.

3. Ninomiya JK, L'Italien G, Criqui MH, Whyte JL, Gamst A, Chen RS. Association of the metabolic syndrome with history of myocardial infarction and stroke in the Third National Health and Nutrition Examination Survey. Circulation 2004; 109: 42-6.

4. Ford ES. Risks for all-cause mortality, cardiovascular disease, and diabetes associated with the metabolic syndrome: a summary of the evidence. Diabetes Care 2005; 28: 1769-78.

5. Jelavic MM, Babic Z, Pintaric $H$. The importance of two metabolic syndrome diagnostic criteria and body fat distribution in predicting clinical severity and prognosis of acute myocardial infarction. Arch Med Sci 2017; 13: 795-806.

6. Ford ES, Giles WH, Dietz WH. Prevalence of the metabolic syndrome among US adults: findings from the third National Health and Nutrition Examination Survey. JAMA 2002; 287: 356-9.

7. Misra A, Khurana L. Obesity and the metabolic syndrome in developing countries. J Clin Endocrinol Metab 2008; 93: S9-30.

8. Florez H, Silva E, Fernandez V, et al. Prevalence and risk factors associated with the metabolic syndrome and dyslipidemia in White, Black, Amerindian and Mixed Hispanics in Zulia State, Venezuela. Diabetes Res Clin Pract 2005; 69: 63-77.

9. Marquezine GF, Oliveira CM, Pereira AC, Krieger JE, Mill JG. Metabolic syndrome determinants in an urban population from Brazil: social class and gender-specific interaction. Int J Cardiol 2008; 129: 259-65.

10. Mattsson N, Ronnemaa T, Juonala M, Viikari JS, Raitakari OT. The prevalence of the metabolic syndrome in young adults. The Cardiovascular Risk in Young Finns Study. J Intern Med 2007; 261: 159-69.

11. Ervin RB, National Center for Health Statistics (U.S.). Prevalence of metabolic syndrome among adults 20 years of age and over, by sex, age, race and ethnicity, and body mass index : United States, 2003-2006. Hyattsville, MD: U.S. Dept. of Health and Human Services, Centers for Disease Control and Prevention, National Center for Health Statistics 2009.

12. Despres JP, Lemieux I. Abdominal obesity and metabolic syndrome. Nature 2006; 444: 881-7.

13. Pelczynska M, Grzelak T, Sperling M, Bogdanski P, Pupek-Musialik D, Czyzewska K. Impact of 25-hydroxyvitamin $D$, free and bioavailable fractions of vitamin $D$, and vitamin $\mathrm{D}$ binding protein levels on metabolic syndrome components. Arch Med Sci 2017; 13: 745-52.

14. Bremer AA, Mietus-Snyder M, Lustig RH. Toward a unifying hypothesis of metabolic syndrome. Pediatrics 2012; 129: 557-70.

15. Alemany M. Utilization of dietary glucose in the metabolic syndrome. Nutr Metab (Lond) 2011; 8: 74.

16. Thyfault JP, Krogh-Madsen R. Metabolic disruptions induced by reduced ambulatory activity in free-living humans. J Appl Physiol (1985) 2011; 111: 1218-24.

17. Wispe JR, Warner BB, Clark JC, et al. Human Mn-superoxide dismutase in pulmonary epithelial cells of transgenic mice confers protection from oxygen injury. J Biol Chem 1992; 267: 23937-41. 
18. Cox AG, Winterbourn CC, Hampton MB. Mitochondrial peroxiredoxin involvement in antioxidant defence and redox signalling. Biochem J 2009; 425: 313-25.

19. Forsberg L, Lyrenas L, de Faire U, Morgenstern R. A common functional C-T substitution polymorphism in the promoter region of the human catalase gene influences transcription factor binding, reporter gene transcription and is correlated to blood catalase levels. Free Radical Biol Med 2001; 30: 500-5.

20. Esih K, Goricar K, Dolzan V, Rener-Primec Z. The association between antioxidant enzyme polymorphisms and cerebral palsy after perinatal hypoxic-ischaemic encephalopathy. Eur J Paediatr Neurol 2016; 20: 704-8.

21. Sutton A, Imbert A, Igoudjil A, et al. The manganese superoxide dismutase Ala16Val dimorphism modulates both mitochondrial import and mRNA stability. Pharmacogenet Genom 2005; 15: 311-9.

22. Takata Y, King IB, Lampe JW, et al. Genetic variation in GPX1 is associated with GPX1 activity in a comprehensive analysis of genetic variations in selenoenzyme genes and their activity and oxidative stress in humans. J Nutr 2012; 142: 419-26.

23. Ho E, Bray TM. Antioxidants, NFkappaB activation, and diabetogenesis. Proc Soc Exp Biol Med 1999; 222: 205-13.

24. Klen J, Goricar K, Janez A, Dolzan V. NLRP3 inflammasome polymorphism and macrovascular complications in type 2 diabetes patients. J Diabetes Res 2015; 2015: 616747

25. Carta S, Penco F, Lavieri R, et al. Cell stress increases ATP release in NLRP3 inflammasome-mediated autoinflammatory diseases, resulting in cytokine imbalance. Proc Natl Acad Sci USA 2015; 112: 2835-40.

26. Sahdo B, Fransen K, Asfaw Idosa B, et al. Cytokine profile in a cohort of healthy blood donors carrying polymorphisms in genes encoding the NLRP3 inflammasome. PLoS One 2013; 8: e75457.

27. Varghese GP, Fransen K, Hurtig-Wennlof A, Bengtsson T, Jansson JH, Sirsjo A. Q705K variant in NLRP3 gene confers protection against myocardial infarction in female individuals. Biomed Rep 2013; 1: 879-82.

28. Verma N, Jain V, Birla S, Jain R, Sharma A. Growth and hormonal profile from birth to adolescence of a girl with aromatase deficiency. J Pediatr Endocrinol Metab 2012; 25: 1185-90.

29. Fontalba A, Martinez-Taboada V, Gutierrez O, et al. Deficiency of the NF-kappaB inhibitor caspase activating and recruitment domain 8 in patients with rheumatoid arthritis is associated with disease severity. J Immunol 2007; 179: 4867-73.

30. Bai Y, Nie S, Jiang G, et al. Regulation of CARD8 expression by ANRIL and association of CARD8 single nucleotide polymorphism rs2043211 (p.C10X) with ischemic stroke. Stroke 2014; 45: 383-8.

31. He F, Rodriguez-Colon S, Fernandez-Mendoza J, et al. Abdominal obesity and metabolic syndrome burden in adolescents: Penn State Children Cohort study. J Clin Densitom 2015; 18: 30-6.

32. Grabar PB, Logar D, Lestan B, Dolzan V. Genetic determinants of methotrexate toxicity in rheumatoid arthritis patients: a study of polymorphisms affecting methotrexate transport and folate metabolism. Eur J Clin Pharmacol 2008; 64: 1057-68.

33. Goricar K, Erculj N, Zadel M, Dolzan V. Genetic polymorphisms in homologous recombination repair genes in healthy Slovenian population and their influence on DNA damage. Radiol Oncol 2012; 46: 46-53.

34. Sarmento RA, Riboldi BP, da Costa Rodrigues T, de Azevedo MJ, de Almeida JC. Development of a quantitative food frequency questionnaire for Brazilian patients with type 2 diabetes. BMC Public Health 2013; 13: 740.

35. Stevilo studentov $\vee$ Sloveniji padlo pod 80000 a se vedno studira skoraj polovica mladih. Slovenia: STA; 2017.

36. Cameron AJ, Shaw JE, Zimmet PZ. The metabolic syndrome: prevalence in worldwide populations. Endocrin Metab Clin 2004; 33: 351-75.

37. Okada R, Yasuda Y, Tsushita K, Wakai K, Hamajima N, Matsuo S. Upper-normal waist circumference is a risk marker for metabolic syndrome in normal-weight subjects. Nutr Metab Cardiovasc Dis 2016; 26: 67-76.

38. Lapice E, Maione S, Patti L, et al. Abdominal adiposity is associated with elevated C-reactive protein independent of BMI in healthy nonobese people. Diabetes Care 2009; 32: 1734-6.

39. Lurbe E, Alvarez V, Redon J. Obesity, body fat distribution, and ambulatory blood pressure in children and adolescents. J Clin Hypertens (Greenwich) 2001; 3: 362-7.

40. Ganpule-Rao A, Joglekar C, Patkar D, et al. Associations of trunk fat depots with insulin resistance, beta cell function and glycaemia: a multiple technique study. PLoS One 2013; 8: e75391.

41. Aljohani NJ. Metabolic syndrome: risk factors among adults in Kingdom of Saudi Arabia. J Fam Commun Med 2014; 21: 170-5.

42. Martino F, Puddu PE, Lamacchia F, et al. Mediterranean diet and physical activity impact on metabolic syndrome among children and adolescents from Southern Italy: contribution from the Calabrian Sierras Community Study (CSCS). Int J Cardiol 2016; 225: 284-8.

43. Anderson AA, Yoo H, Franke WD. Associations of physical activity and obesity with the risk of developing the metabolic syndrome in law enforcement officers. J Occup Environ Med 2016; 58: 946-51.

44. Espelt A, Borrell C, Roskam AJ, et al. Socioeconomic inequalities in diabetes mellitus across Europe at the beginning of the 21st century. Diabetologia 2008; 51 : 1971-9.

45. Yang JJ, Yoon HS, Lee SA, et al. Metabolic syndrome and sex-specific socio-economic disparities in childhood and adulthood: the Korea National Health and Nutrition Examination Surveys. Diabet Med 2014; 31: 1399-409.

46. Asghari G, Yuzbashian E, Mirmiran P, Mahmoodi B, Azizi F. Fast food intake increases the incidence of metabolic syndrome in children and adolescents: Tehran Lipid and Glucose Study. PLoS One 2015; 10: e0139641.

47. Burger KNJ, Beulens JWJ, van der Schouw YT, et al. Dietary fiber, carbohydrate quality and quantity, and mortality risk of individuals with diabetes mellitus. PLoS One 2012; 7: e43127.

48. Drehmer M, Odegaard AO, Schmidt MI, et al. Brazilian dietary patterns and the dietary approaches to stop hypertension (DASH) diet-relationship with metabolic syndrome and newly diagnosed diabetes in the ELSA-Brasil study. Diabetol Metab Syndr 2017; 9: 13.

49. Patti AM, Al-Rasadi K, Giglio RV, et al. Natural approaches in metabolic syndrome management. Arch Med Sci 2018; 14: 422-41.

50. Maintinguer Norde M, Oki E, Ferreira Carioca AA, et al. Influence of IL1B, IL6 and IL10 gene variants and plasma fatty acid interaction on metabolic syndrome risk in a cross-sectional population-based study. Clin Nutr 2018; 37: 659-66.

51. Pennathur S, Jaiswal M, White EA, et al. Structured lifestyle intervention in patients with the metabolic syndrome mitigates oxidative stress but fails to improve measures of cardiovascular autonomic neuropathy. J Diabetes Complications 2017; 31: 1437-43. 
52. da Fonseca LJ, Nunes-Souza V, Guedes Gda S, Schettino-Silva G, Mota-Gomes MA, Rabelo LA. Oxidative status imbalance in patients with metabolic syndrome: role of the myeloperoxidase/hydrogen peroxide axis. Oxid Med Cell Longev 2014; 2014: 898501.

53. Saiki O, Kuhara M, Kikuchi N, Shiraishi S, Uda H. Evaluation of lasting high levels of CRP among the patients with metabolic syndrome. Inflammation 2012; 35: 730-5.

54. Cavalieri M, Ropele S, Petrovic K, et al. Metabolic syndrome, brain magnetic resonance imaging, and cognition. Diabetes Care 2010; 33: 2489-95.

55. Yamamoto K, Okazaki A, Ohmori S. The relationship between psychosocial stress, age, BMI, CRP, lifestyle, and the metabolic syndrome in apparently healthy subjects. J Physiol Anthropol 2011; 30: 15-22.

56. Oh EG, Bang SY, Kim SH, et al. Therapeutic lifestyle modification program reduces plasma levels of the chemokines CRP and MCP-1 in subjects with metabolic syndrome. Biol Res Nurs 2013; 15: 48-55.

57. Gaskins AJ, Wilchesky M, Mumford SL, et al. Endogenous reproductive hormones and $\mathrm{C}$-reactive protein across the menstrual cycle: the BioCycle Study. Am J Epidemiol 2012; 175: 423-31.

58. Zaki ME, El-Bassyouni HT, El-Gammal M, Kamal S. Indicators of the metabolic syndrome in obese adolescents. Arch Med Sci 2015; 11: 92-8.

59. Eisenmann JC. On the use of a continuous metabolic syndrome score in pediatric research. Cardiovasc Diabetol 2008; 7: 17 .

60. Vukovic R, Milenkovic T, Stojan G, et al. Pediatric siMS score: a new, simple and accurate continuous metabolic syndrome score for everyday use in pediatrics. PLoS One 2017; 12: e0189232.

61. Shaw JE, Sicree RA, Zimmet PZ. Global estimates of the prevalence of diabetes for 2010 and 2030. Diabetes Res Clin Pract 2010; 87: 4-14.

62. Ricci G, Pirillo I, Tomassoni D, Sirignano A, Grappasonni I. Metabolic syndrome, hypertension, and nervous system injury: epidemiological correlates. Clin Exp Hypertens 2017; 39: 8-16 